\title{
Memori dalam Multitasking
}

\author{
Ni Made Swasti Wulanyani ${ }^{1}$ \\ Program Studi Psikologi \\ Fakultas Kedokteran Universitas Udayana
}

\section{Pengantar}

Multitasking atau tugas berganda menyiratkan adanya lebih dari satu tugas di dalamnya. Salvucci dan Taatgen (2011) menambahkan bahwa kondisi tugas berganda adalah adanya beberapa tugas yang independen dan tidak berhubungan yang dilakukan dalam waktu yang bersamaan. Hal inilah yang membedakannya dengan tugas kompleks. Selanjutnya Appelbaum dan Marchionni (2008) memandang tugas berganda menjadi dua jenis yaitu tugas ganda (dual task) atau dua tugas yang dilakukan bersamaan dan switching task atau lebih dari satu tugas yang dilakukan dengan beralih diantara tugas-tugas tersebut. Sementara Salvucci dan Taatgen (2011) menyebutnya sebagai tugas berganda bersamaan (concurrent multitasking) yaitu setiap tugas berlangsung bersamaan/simultan atau hanya dengan interupsi singkat. Bentuk lainnya adalah tugas berganda sekuensial (sequential multitasking) yaitu individu memberikan perhatian yang lebih lama pada satu tugas sebelum berpindah pada tugas lain, meskipun tetap terjadi tumpang tindih perhatian.

Tugas berganda digambarkan dalam sebuah kontinum seperti pada Gambar 1.

Berdasarkan Gambar 1, sisi kiri menunjukkan kegiatan dimana orang beralih

\footnotetext{
Korespondensi mengenai isi artikel ini dapat dilakukan melalui: swastiwulan@gmail.com
}

diantara tugas-tugas dengan interval waktu yang sangat cepat, hanya dalam hitungan beberapa detik saja. Semakin ke kanan, proses peralihan tugas-tugas yang dilakukan berlangsung semakin lama. Pada akhirnya sisi yang paling kanan menunjukkan kegiatan dimana orang beralih setelah melakukan satu kegiatan dalam waktu cukup lama sebelum akhirnya beralih ke kegiatan lain.

Meskipun dikatakan kurang sehat, namun faktanya kemampuan multitasking banyak dibutuhkan dalam kegiatan seharihari (Burgess, 2000). Dalam rutinitas ini, banyak orang mengandalkan kemampuan mereka untuk mengatur 'tindakan ke depan' sehingga mereka dapat menyelesaikan beberapa aktivitas pada waktu yang tepat dan efisien. Kemampuan untuk memprioritaskan, mengatur dan melaksanakan sejumlah tugas yang berbeda dalam waktu terbatas juga dikenal sebagai kemampuan multitasking (Burgess, Veitch, Costello, \& Shallice, 2000). Pentingnya kemampuan ini ditegaskan oleh Bechara, Tranel, dan Damasio (2000), bahwa orangorang yang memiliki gangguan pada kemampuan untuk mengatur beberapa tindakan telah terbukti memiliki kesulitan untuk hidup mandiri. Kondisi multitasking dapat diilustrasikan seperti orang yang sedang memasak makanan. Memasak makanan membutuhkan sejumlah langkahlangkah dengan tujuan masing-masing. Dimulai dari mempersiapkan bahan olahan, diikuti dengan proses yang berbeda- 


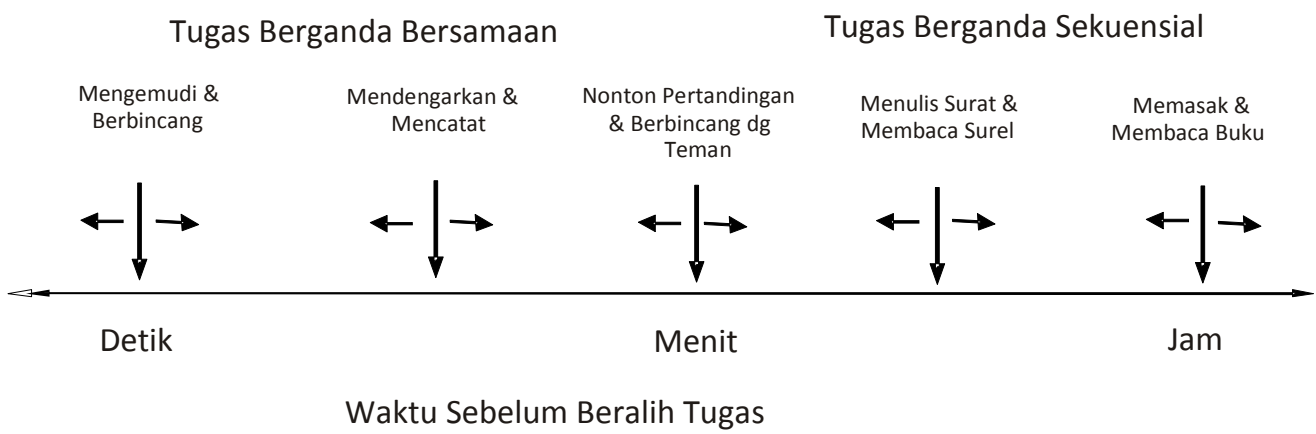

Gambar 1. Kontinum tugas berganda (Salvucci \& Taatgen, 2009)

beda dengan waktu olah yang berbeda pula, sehingga harus selalu dipantau dan dikoordinasikan. Insiden tak terduga mungkin juga terjadi, seperti kurangnya bahan pendukung sehingga rencana harus diubah.

Salah satu penelitian menunjukkan bahwa kemampuan multitasking dipengaruhi oleh faktor kecerdasan, kepribadian dan cara kerja (Wulanyani, 2014). Secara spesifik, faktor kecerdasan juga berkaitan dengan aspek memori sebagai salah satu faktor kontrol kognitif. Berikut akan dibahas mengenai memori yang berkaitan dengan multitasking.

\section{Prospective memory}

Prospective memory adalah kemampuan mengingat untuk melakukan sesuatu di waktu mendatang. Intensionalitas atau prospective memory mengacu pada proses kognitif yang kompleks yang terlibat dalam pengambilan dan pelaksanaan intensi yang dibentuk sebelumnya, untuk dilakukan pada waktu yang tepat di masa depan (Kvavilashvili \& Ellis, 1996). Contoh sehari-hari prospective memory misalnya seorang anak mengingat untuk meminjam buku dari perpustakaan sekolah yang diperlukannya untuk mengerjakan pekerjaan rumah, atau mengingat untuk mempersiapkan perjalanan wisata keesokan harinya. Dalam ilustrasi proses memasak sebelumnya, prospective memory ini terjadi saat individu tersebut berniat untuk kembali memeriksa kue di pemanggang 30 menit lagi. Proses ini tentu membutuhkan pengetahuan tentang faktor-faktor potensial yang dapat menghambat kinerja. Perencanaan tindakan dan penentuan waktu yang tepat membutuhkan kemampuan organisasi (Burgess et al., 2000; Carey, Woods, Rippeth, Heaton \& Grant, 2006). Tahap selanjutnya, sumber daya perhatian mulai dialokasikan untuk tugas lain yang mungkin muncul. Dalam tahap ini mulai dibuat strategi untuk menilai apakah keadaan sudah tepat untuk melaksanakan rencana sebuah tindakan (Carey et al., 2006).

Peran prospective memory dalam kemampuan untuk multitasking lebih lanjut dibuktikan oleh individu dengan gangguan aplikasi strategi dan organisasi. Kegagalan ini ditandai oleh ketidakmampuan untuk memenuhi tenggat waktu dan untuk menepati janji (Burgess, 2000). Dalam perspektif neurosains, multitasking terkait dengan bagian otak yang bernama korteks prefrontal dan area Brodmann 10. Bagian otak yang disebut dengan korteks prefrontal adalah daerah kortikal di anterior lobus frontal terhadap korteks motorik asosiasi dan primer. Bagian otak ini meningkat ukurannya seiring dengan perkembangan filogenetik. Pada manusia, korteks prefrontal terlibat di dalam perencanaan perilaku kognitif yang kompleks, 
ekspresi kepribadian, dan perilaku sosial. (Burgess, Quayle \& Frith, 2001)

Satu fungsi yang dihubungkan dengan korteks prefrontal adalah multitasking, terutama seleksi dan pemeliharaan beragam tujuan internal perintah yang lebih tinggi sementara sub-tujuan lainnya sedang dilakukan. Pemeliharaan dan pencarian fleksibel dari beragam tujuan perintah yang lebih tinggi memungkinkan kita untuk menyesuaikan perilaku kita terhadap rencana internal, dibandingkan dengan selalu beresponss terhadap lingkungan eksternal.

Area Brodmann 10, juga dikenal sebagai kutub frontal (frontopolar cortex) atau korteks prefrontal anterior/rostral, merupakan daerah terbesar dan paling anterior di korteks prefrontal manusia. AB10 memainkan peranan penting di dalam kesadaran manusia. Beberapa neurosaintis meletakkan area Brodmann 10 di puncak hirarki (the top of a frontal processing hierarchy). Perannya adalah untuk menjaga tujuan primer di pikiran sementara sedang menyelidiki dan menyelesaikan tujuantujuan sekunder. Singkatnya, area Brodmann 10 berperan penting di dalam working memory dan dual-task performance, yang ada dalam situasi multitasking.

Saat ini, bukti menunjukkan bahwa cingulate anterior, daerah Brodmann 10 dan daerah anatomis yang berdekatan serta prefrontal dorsolateral korteks, masingmasing memberikan kontribusi pada aspek kinerja multitasking (Burgess, et al., 2001). Lebih khusus, daerah Brodmann 10 berkaitan dengan koordinasi informasi dan transfer antara beberapa operasi kognitif, sebuah fungsi yang tampaknya akan sangat terkait dengan multitasking (Ramnani \& Owen, 2004).

Beragam data dari studi neuroimaging fungsional menunjukkan bahwa gangguan fungsi multitasking dan kekurangan perencanaan ditunjukkan oleh orang dengan kerusakan korteks frontal yang luas. Kerusakan area Brodmann 10 menyebabkan gangguan untuk mengelola tujuan-tujuan dari beberapa aktivitas. Riset menunjukkan sekelompok orang dengan lesi frontal, gangguan multitasking berkorelasi dengan tingkat kerusakan area Brodmann 10. Beberapa riset terbaru menunjukkan relasi antara korteks prefrontal dan prospective memory (Burgess, et al., 2001).

\section{Working memory}

Working memory adalah sumber daya ingatan yang terbatas pada kapasitas maupun durasi untuk memproses informasi (Bayliss et al., 2003). Fungsinya adalah sebagai tempat penyimpanan informasi sementara untuk menyelesaikan tugas tertentu. Memori ini juga berkaitan dengan pengalihan sumber perhatian (Conlin, Gathercole, \& Adams, 2005). Oleh karena itu memori ini juga menjadi kunci dalam multitasking. Working memory akan aktif manakala ada informasi pesaing (Baddeley, 1990). Kondisi ini seperti halnya yang terjadi dalam multitasking yaitu adanya beberapa informasi yang harus diolah pada saat bersamaan.

Keterlibatan working memory pada prospective memory didukung oleh karya Smith (2003) yang menemukan bahwa waktu responss akan melambat saat muncul kebutuhan untuk melakukan tugas prospektif. Perlambatan waktu respons berhubungan negatif dengan kapasitas working memory pada individu. Pecahnya perhatian pada saat melakukan multitasking akan meningkatkan kebutuhan working memory (Einstein, et al., 1997)

Terkait dengan working memory, terdapat suatu proses yang dinamakan kontrol inhibisi. Inhibisi adalah sumber daya yang menekan info yang tidak relevan di dalam 
working memory. Hal ini secara khusus dapat dibuktikan dalan situasi kompleks saat inhibisi diperlukan untuk menjaga agar info yang tidak relevan tidak menghabiskan kapasitas working memory yang terbatas (Wilson, Kipp, \& Daniels, 2003). Pendapat ini didukung oleh penemuan bahwa sebuah rangkaian syaraf yang mendukung working memory akan aktif selama proses inhibisi (Bunge et al., 2001).

Inhibisi juga memberikan implikasi pada tugas-tugas prospective memory yang membutuhkan kontrol strategi tingkat tinggi (Martin, Kliegel, \& McDaniel, 2003). Individu merasa lebih mudah untuk beralih diantara tugas-tugas manakala sebuah tugas yang sekarang sedang dikerjakan tidak diinterupsi untuk dilakukan dimasa mendatang (Kvavilashvili et al., 2001). Mekanisme inhibisi dibutuhkan untuk menginterupsi sebuah tugas yang sedang dikerjakan dalam rangka 'mempersilakan' kegiatan yang lain untuk muncul (Kerns, 1999). Inhibisi diperlukan untuk menginterupsi performa beberapa kali selama melakukan pengalihan tugas dalam multitasking.

Inhibisi sering disamakan dengan interferensi tetapi sebenarnya berbeda. Inhibisi adalah proses supresi pada isi dari working memory yang tidak relevan, sedangkan interferensi adalah pencegahan masuknya informasi yang tidak relevan atau stimulus pengganggu ke dalam working memory melalui sebuah mekanisme pintu gerbang (Harnishfeger, 1995; Wilson \& Kipp, 2003).

\section{Penutup}

Ulasan ini dan studi lainnya memberikan bukti yang mendukung hubungan antara kinerja multitasking dan kemampuan memori prospektif, serta hal-hal yang terkait dengan working memory
(Ramnani \& Owen, 2004). Mengingat adanya hubungan erat antara inhibisi, prospective memory dan working memory, ada kemungkinan bahwa pengembangan kemampuan multitasking tergantung pada proses kontrol inhibisi.

\section{Daftar Pustaka}

Appelbaum, S. H., \& Marchionni, A. (2008). The Multi-tasking paradox: perceptions, problems and strategies. Management Decision, 46(9), 1313-1325. http://dx.doi.org/10.1108/002517408109 11966.

Baddeley, A. D. (1990). Human memory: Theory and practice. Boston: Allyn and Bacon.

Bayliss, D. M., Jarrold, C., Gunn, D. M., \& Baddeley, A. D. (2003). The complexities of complex span: Explaining individual differences in working memory in children and adults. Journal of Experimental Psychology: General, 132, 71-92.

Bunge, S. A., Ochsner, K. N., Desmond, J. E., Glover, G. H., \& Gabrieli, J. D. E. (2001). Prefrontal regions involved in keeping information in and out of mind. Brain, 124, 2074-2086.

Burgess, P. W. (2000). Strategy application disorder: the role of the frontal lobe in human multitasking research. Psychological Research, 63, 279-288.

Burgess, P. W., Quayle, A., \& Frith, C. D. (2001). Brain regions involved in prospective memory as determined by positron emission tomography. Neuropsychologia, 39, 545-555.

Carey, C. L., Woods, S. P., Rippeth, J. D., Heaton, R. K., Grant, I. \& HNRC Group. (2006). Prospective memory in HIV-1 infection. Journal of Clinical and Experimental Neuropsychology, 28, 536548. 


\section{WULANYANI}

Conlin, J. A., Gathercole, S. E., \& Adams, J. W. (2005). Children's working memory: Investigating performance limitations in complex span tasks. Journal of Experimental Child Psychology, 90, 303317.

Einstein, G. O., Smith, R. E., McDaniel, M. A., \& Shaw, P. (1997). Aging and prospective memory: The influence of increased task demands at encoding and retrieval. Psychology and Aging, 12, 479-488.

Friedman, N. P., \& Miyake, A. (2004). The relations among inhibition and interference control functions: A latent variable analysis. Journal of Experimental Psychology: General, 133, 101-135.

Harnishfeger, K. K. (1995). The development of cognitive inhibition: Theories, definitions, and research evidence. In F.N. Dempster \& C.J. Brainerd (Eds), Interference and inhibition in cognition (pp. 175-204). San Diego, CA: Academic Press.

Kerns, K. A. (2000). The CyberCruiser: An investigation of development of prospective memory in children. Journal of International Neuropsychological Society, 6, 62-70.

Kvavilashvili, L. Messer, D., \& Ebdon, P. (2001). Prospective memory in children: The effects of age and task interruption. Developmental Psychology, 37(3), 418-430.
Martin, M., Kliegel, M., \& McDaniel, M. A. (2003). The involvement of executive functions in prospective memory performance of adults. International Journal of Psychology, 38(4), 195-206.

Nigg, J. T. (2001). Is ADHD a disinhibitory disorder? Psychological Bulletin, 127, 571- 598.

Ramnani, N., \& Owen, A.M. (2004). Anterior prefrontal cortex: Insights into function from anatomy and neuroimaging. NatureReviews Neuroscience, 5 , 184-194.

Salvucci, D. D., \& Taatgen, N. A. (2011). The Multitasking Mind. New York: Oxford University Press.

Smith, R. E. (2003). The cost of remembering to remember in event-based prospective memory: Investigating the capacity demands of delayed intention performance. Journal of Experimental Psychology: Learning, Memory, and Cognition, 29, 347-361.

Wilson, S. P., Kipp, K., \& Daniels, J. (2003). Task demands and age-related differences in retrieval and responsse inhibition. British Journal of Developmental Psychology, 21, 599-613.

Wulanyani, N. M. S. (2014). Faktor kecerdasan, kepribadian dan cara kerja yang memengaruhi performansi tugas berganda. (Disertasi, tidak dipublikasikan). Yogyakarta. Fakultas Psikologi UGM 